\title{
A Density Functional Theory Study of Methoxy and Atomic Hydrogen Chemisorption on Au(100) Surface
}

\author{
M. N'dollo ${ }^{1}$, P. S. Moussounda ${ }^{1 *}$, T. Dintzer ${ }^{2}$, F. Garin ${ }^{2}$ \\ ${ }^{1}$ Groupe de Simulations Numériques en Magnétisme et Catalyse, Département de Physique, \\ Faculté des Sciences, Université Marien Ngouabi, Brazzaville, Congo \\ ${ }^{2}$ Laboratoire des Matériaux, Surfaces et Procédés pour la Catalyse (LMSPC), \\ Université de Strasbourg, Strasbourg, France \\ Email: *ps moussounda@yahoo.fr
}

Received December 26, 2012; revised January 27, 2013; accepted February 7, 2013

\begin{abstract}
The adsorption of $\mathrm{CH}_{3} \mathrm{O}$ and $\mathrm{H}$ on the (100) facet of gold was studied using self-consistent periodic density functional theory (DFT-GGA) calculations. The best binding site, energy, and structural parameter, as well as the local density of states, of each species were determined. $\mathrm{CH}_{3} \mathrm{O}$ is predicted to strongly adsorb on the bridge and hollow sites, with the bridge site as preferred one, with one of the hydrogen atoms pointing toward a fourfold vacancy (bridge-H hollow). The top site was found to be unstable, the $\mathrm{CH}_{3} \mathrm{O}$ radical moving to the bridge $-\mathrm{H}$ top site during geometry optimization. Adsorption of $\mathrm{H}$ is unstable on the hollow site, the atom moving to the bridge site during geometry optimization. The 4-layer slab is predicted to be endothermic with respect to gaseous $\mathrm{H}_{2}$ and a clean Au surface.
\end{abstract}

Keywords: Chemisorption; Density Functional Calculations; Gold; Methoxy; Hydrogen

\section{Introduction}

The methoxy group $\mathrm{CH}_{3} \mathrm{O}$ and hydrogen $\mathrm{H}$ species have been identified as two intermediates in the decomposition of methanol through an initial O-H bond scission on several transition metal surfaces. For methoxy group $\mathrm{CH}_{3} \mathrm{O}$, it appears as an intermediate also in formaldehyde production and in the synthesis of hydrogenated products of $\mathrm{CO}$ or its inverse reaction. For catalytic reactions, knowledge of the adsorption geometry of reactants is crucial since it decides on the energy changes during the reaction as well as on the capability of adsorbed species to interact with another one.

Over the last two decades, a number of experimental studies on methoxy over various metal surfaces have been performed using several techniques. Specifically, methoxy on $\mathrm{Cu}(110)$ [1-4], $\mathrm{Cu}(111)$ [5-7], $\mathrm{Cu}(100)$ [813], $\mathrm{Ag}(111)$ [14], Ni(111) [15], Ni(110) [16,17], Pt(111) [18] has been studied extensively by using X-ray photoelectron diffraction (XPD), reflection absorption infrared spectroscopy (RAIRS), near-edge X-ray absorption fine structure (NEXAFS), temperature-programmed desorption (TPD), low-energy electron diffraction (LEED), scanning tunneling spectroscopy (STM), high-resolution electron energy-loss spectroscopy (HREELS), energy scanned photoelectron diffraction (PED) and surface

${ }^{*}$ Corresponding author. extended X-ray absorption fine structure (SEXAFS). We note that the XPD [5], SEXAFS [6] and NEXAFS [6] studies for $\mathrm{CH}_{3} \mathrm{O} / \mathrm{Cu}(111)$ and RAIRS [14] for $\mathrm{CH}_{3} \mathrm{O} /$ $\mathrm{Ag}(111)$, showed that the $\mathrm{CH}_{3} \mathrm{O}$ radical resides in threefold hollow site and the $\mathrm{C}-\mathrm{O}$ bond is normal to the surface. Whereas, in the PED study [7], it was also found that the $\mathrm{CH}_{3} \mathrm{O}$ radical adopted a geometry in which the $\mathrm{C}-\mathrm{O}$ bond was close to perpendicular to the surface and the $\mathrm{O}$ atom occupied a threefold hollow site, fcc. Despite the existence of a large number of studies, conflicting structural assignments still exist. The NEXAFS study of Outka et al. [9] shows that methoxy $\mathrm{C}-\mathrm{O}$ axis will be found with an angle of $20^{\circ}-40^{\circ}$ relative to the $\mathrm{Cu}(100)$ surface normal. Using the infrared spectroscopy [10,11], Ryberg also found that methoxy is tilted when adsorbed on this surface. Camplin et al. [12], using the RAIRS technique, found the $\mathrm{C}-\mathrm{O}$ methoxy radical bond to be perpendicular to the $\mathrm{Cu}(100)$ surface. A later study of Lindner et al. [13] with a combined NEXAFS and photoelectron research concluded that the $\mathrm{C}-\mathrm{O}$ axis is perpendicular to the surface and that a low symmetry adsorption site between the bridge and the 4-fold hollow site is occupied.

Several theoretical studies have also been done on the methoxy - metal surface interactions [19-28]. A manyelectron embedding theory, at the $a b$ initio configuration interaction level, was used to study the adsorption of 
methoxy on the $\mathrm{Ni}(111)$ surface [20]. That work showed how $\mathrm{CH}_{3} \mathrm{O}$ is adsorbed at 3-fold hollow sites with the $\mathrm{C}-\mathrm{O}$ axis tilted $5^{\circ}$ from the normal to the surface plane. Wang et al. [22] used density functional theory (DFT) to determine $\mathrm{CH}_{3} \mathrm{O} / \mathrm{Ni}(111)$ properties. They found that $\mathrm{CH}_{3} \mathrm{O}$ interacts with the surface through oxygen and has a binding energy of $2.58 \mathrm{eV}$ for the threefold fcc hollow site. Witko et al. [19,21] have studied the adsorption of $\mathrm{CH}_{3} \mathrm{O}$ on $\mathrm{Cu}(111)$ surface by performing ab initio HFLCAO calculations. Again it was found that $\mathrm{CH}_{3} \mathrm{O}$ is usually adsorbed at 3-fold hollow sites with a slight preference for fcc sites. On $\mathrm{Cu}(111)$, the $\mathrm{C}-\mathrm{O}$ axis lies perpendicular to the metal surface and the calculated adsorption energy is $2.80 \mathrm{eV}$. Gomes and coworker [23] have studied the same adsorption of $\mathrm{CH}_{3} \mathrm{O}$ on $\mathrm{Cu}(111)$ surface, using their DFT approach and cluster models. They reported that three-fold hollow sites are the most stable position for methoxy, with fcc and hep hollows having binding energies of $2.50 \mathrm{eV}$ and $2.18 \mathrm{eV}$, respectively. Using a DFT approach Greeley and Mavrikakis [24] examined the reaction of $\mathrm{CH}_{3} \mathrm{O}$ on $\mathrm{Pt}(111)$ top site. They evaluated chemisorption energy around $1.54 \mathrm{eV}$. Recently, Pang et al. [25] have carried out the methoxy adsorption on $\mathrm{Ni}(111), \mathrm{Ni}(110)$ and $\mathrm{Ni}(100)$ surfaces using a DFT method. Very little ab initio and DFT studies have been carried out for methoxy adsorbed on Au. Gomes and Gomes [23] found that $\mathrm{CH}_{3} \mathrm{O}$ binds at all high symmetric sites of $\mathrm{Au}$ (111) with a preference for the hollow fcc site. The corresponding chemisorption energy for this site was found to be $0.89 \mathrm{eV}$. With a same surface, Chen et al. [26] found that the bridge site is most stable. The corresponding binding energy was calculated to be $0.99 \mathrm{eV}$. To the best of our knowledge, there is no theoretical study of $\mathrm{CH}_{3} \mathrm{O}$ adsorption on the $\mathrm{Au}(100)$ surface in the literature.

Atomic hydrogen $(\mathrm{H})$ is probably one of the most extensively studied adsorbate in a large number of catalytic processes. Details on the $\mathrm{H}$ chemisorption on transition metal surfaces (TMS) can be found in the literature [29, 30]. A series of TPD, LEED, STM, and electron energy loss spectroscopy (EELS) studies of $\mathrm{H}$ adsorption have performed by several groups on Ni(111) [31-33]. Schick et al. have applied HREELS to study H on $\operatorname{Ir}(111)$ [31]. Techniques such as LEED [34-37], HREELS [38], LERS [39], UPS [40] and calorimetric measurements [41] have been applied to investigate the adsorption of $\mathrm{H}$ on the $\operatorname{Pt}(100), \operatorname{Pt}(110)$, and Pt(111) surfaces. A number of theoretical studies have also performed for H on TMS. Effective medium theory study for $\mathrm{H}$ adsorption on $\mathrm{Ni}(111)$, $\mathrm{Ni}(100), \mathrm{W}(100)$ and $\mathrm{W}(110)$ has been reported by Nordlander et al. [42]. Jiang and Carter [43] have performed a DFT study of $\mathrm{H}$ adsorption on $\mathrm{Fe}(110)$. Extensive $a b$ initio calculations and the DFT method have been used to investigate the adsorption of hydrogen on $\mathrm{Pt}(111)$ [44-
47], Pt(110) [47,48], Pt(100) [47,49,50], Ni(100) [49], $\mathrm{Ni}(111)$ [51,52] and $\mathrm{Cu}(001)$ [53]. To our best knowledge, there are no studies at DFT level of hydrogen adsorption on $\mathrm{Au}(100)$ surface.

In this contribution, we present a systematic DFT study of the properties of atomic $\mathrm{H}$ and $\mathrm{CH}_{3} \mathrm{O}$ radical on the $\mathrm{Au}(100)$. Our paper is organized as follows. Section 2 gives the details of the computational method. The results and discussions are followed in Section 3. Section 4 concludes with a short summary.

\section{Computational Method}

We are based our DFT calculations on the DACAPO ab initio package [54]. A $(2 \times 2)$ unit cell is used to construct a four or five-layer $\mathrm{Au}(100)$ slab. This corresponds to a surface coverage of $1 / 4 \mathrm{ML}$ when there is only one adsorbate per unit cell. The unit cell is repeated in super cell with successive slabs separated by a vacuum region of $13 \AA$. Adsorption is allowed on only one of the two exposed surfaces. The top layers of the slab and the adsorbate were allowed to relax. The maximum force criterion of $0.05 \mathrm{eV} / \AA$ was considered for convergence. The surface irreducible Brillouin zone was sampled by 18 special k-points using the $(6 \times 6 \times 1)$ Monkhorst-Pack grids.

The Kohn-Sham one-electron valence states are expanded in a basis of plane waves with kinetic energies up to $400 \mathrm{eV}$, and ionic cores were described by ultra soft pseudo potentials [55]. All calculations were performed non-spin polarized. The exchange-correlation potential and energy are described self-consistently using GGAPW91 functional [56]. The electron density is determined by iterative diagonalization of the Kohn-Sham Hamiltonian, Fermi-population of the Kohn-Sham states $\left(k_{B} T=0.1 \mathrm{eV}\right)$ of the resulting electron density. Total energies are extrapolated to $k_{B} T=0 \mathrm{eV}$.

Using DFT as described above yields a bulk lattice constant of $\mathrm{Au}$ of $4.18 \AA$, to be compared with the experimental value of $4.08 \AA$ [56]. Our rather high result is in perfect agreement with other theoretical evaluation using similar methods (4.17 $\AA$ [58] or $4.19 \AA$ [59]).

\section{Results and Discussion}

In this section we describe the properties of the adsorbates studied, including the binding energies, site preferences, geometries, and local density of states (LDOS), and we compare these results with theoretical or experimental data available on transition and noble metal surfaces.

\section{1. $\mathrm{CH}_{3} \mathrm{O}$ Chemisorption on $\mathrm{Au}(100)$}

\subsubsection{Chemisorption Energies}

As usual, the adsorption energy $\left(E_{\mathrm{ads}}\right)$ is evaluated as: 


$$
E_{\text {ads }}=E_{\mathrm{CH}_{3} \mathrm{O}}+E_{\text {slab }}-E_{\mathrm{CH}_{3} \mathrm{O} / \text { slab }}
$$

where $E_{\mathrm{CH}_{3} \mathrm{O}}$ is the total energy of the free $\mathrm{CH}_{3} \mathrm{O}$ radical in the gas phase, $E_{\text {slab }}$ is the total energy of the clean $\mathrm{Au}$ slab and $E_{\mathrm{CH}_{3} \mathrm{O} / \mathrm{slab}}$ is the total energy of the $\mathrm{CH}_{3} \mathrm{O} / \mathrm{Au}$ system. With this definition, a positive $E_{\text {ads }}$ corresponds to a stable adsorption on the slab. The energy of the isolated $\mathrm{CH}_{3} \mathrm{O}$ radical was determined by performing calculations on a single molecule in a cubic cell with $20 \AA$ parameter.

The adsorption of $\mathrm{CH}_{3} \mathrm{O}$ on $\mathrm{Au}(100)$ at high-symmetry top, bridge and hollow sites, as shown in Figure 1, were investigated. For the bridge site, two different hydrogen orientations were considered: one of the $\mathrm{H}$ atoms in the $\mathrm{CH}_{3}$ group points either toward the nearest-neighbor $\mathrm{Au}$ atom (bridge-H top) or toward a fourfold vacancy (bridge-H hollow).

Adsorption energies for $\mathrm{CH}_{3} \mathrm{O}$ radical at the hollow, bridge- $\mathrm{H}$ top and bridge- $\mathrm{H}$ hollow, calculated using different numbers of layers in the slab for methoxy coverage of $0.25 \mathrm{ML}$ are listed in Table 1. The top site was found to be unstable, the $\mathrm{CH}_{3} \mathrm{O}$ radical moving to the hollow site during geometry optimization. From Table 1, it can be found that the adsorption energy of $\mathrm{CH}_{3} \mathrm{O}$ increases by $0.586 \mathrm{eV}$ from 4 to 5-layer slab, for all adsorption sites. In addition, one can see from this table that the most stable site for $\mathrm{CH}_{3} \mathrm{O}$ adsorption on $\mathrm{Au}(100)$

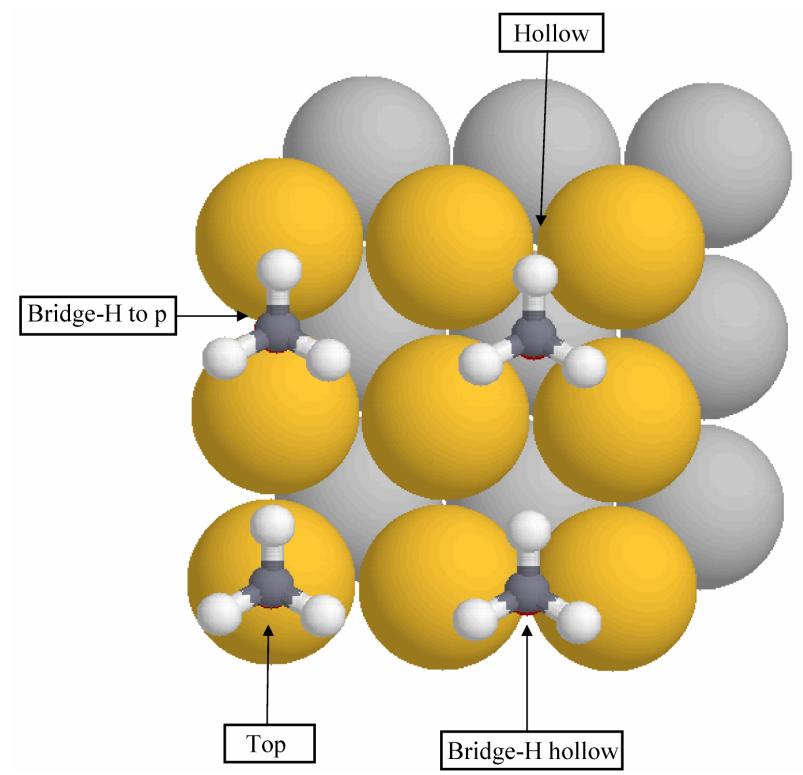

Figure 1. Top view of three high-symmetry adsorption geometries of $\mathrm{CH}_{3} \mathrm{O}$ on the $\mathrm{Au}(100)$ surface. The indicated adsorption sites are the top, bridge and hollow sites. For the bridge site, two different hydrogen orientations were considered: one of the $\mathrm{H}$ atoms in the $\mathrm{CH}_{3}$ group points either toward the nearest-neighbor $\mathrm{Au}$ atom (bridge-H top) or toward a fourfold vacancy (bridge-H hollow) (For interpretation of the references to color in this figure legend, the reader is referred to the web version of the article). is the bridge site with one of the hydrogen atoms pointing toward a fourfold vacancy (bridge-H hollow), at four or five layers of Au. The corresponding adsorption energy for this site was found $1.727 \mathrm{eV}$ (4-layer slab) and $2.314 \mathrm{eV}$ (5-layer slab). The bridge-H top is significantly less stable by $0.153 \mathrm{eV}$. The adsorption energy difference between bridge- $\mathrm{H}$ hollow and hollow sites is only 30 meV. No calculations of $\mathrm{CH}_{3} \mathrm{O}$ radical adsorption on $\mathrm{Au}(100)$ have been published. There are theoretical results for adsorption in the bridge site on the $\mathrm{Au}(111)$, Ni(111), Ni(110), Ni(100), Cu(111), Cu(110) and $\mathrm{Cu}(100)$ surfaces. Gomes and Gomes [23] used a cluster model to study the adsorption of $\mathrm{CH}_{3} \mathrm{O}$ on $\mathrm{Au}(111)$ surface and predicted a chemisorption energy of $0.471 \mathrm{eV}$. For the same surface, Chen et al. [26], using ab initio DFT-GGA calculations with three-layer slab, reported adsorption energy of $0.999 \mathrm{eV}$ for coverage of 1/6 ML. The discrepancy in binding energies may be due to the model effect and the computational methodology (slab vs. cluster). Pang et al. [25] have described the methoxy adsorption on $\mathrm{Ni}(111), \mathrm{Ni}(100)$ and $\mathrm{Ni}(110)$ with non-spin-polarized calculations elaborately, and found the adsorption energy of $2.292 \mathrm{eV}, 2.478 \mathrm{eV}, 2.978 \mathrm{eV}$ (in the short-bridge) and $2.281 \mathrm{eV}$ (in the long-bridge) at $1 / 6$ ML, respectively. In the case of methoxy adsorption on $\mathrm{Cu}(111)$ surface, Gomes et al. [23] and Chen et al. [27] found the adsorption energies of $2.036 \mathrm{eV}$ and $2.363 \mathrm{eV}$, respectively. For the $\mathrm{Cu}(100)$ and $\mathrm{Cu}(110)$ surfaces, Pick [28], using $a b$ initio DFT-GGA calculations with fivelayer $\mathrm{Cu}$ slabs, obtained the binding energies of $2.540 \mathrm{eV}$, $2.690 \mathrm{eV}$ (in the short-bridge) and $2.350 \mathrm{eV}$ (in the longbridge), respectively. These calculated chemisorption energies are much higher than our results.

\subsubsection{Geometric Parameters}

Now turn our attention to the geometric parameters. First of all, we checked that the properties of the isolated $\mathrm{CH}_{3} \mathrm{O}$ were accurately reproduced. Table 2 compares our calculated and previous theoretical [25] bond lengths and bond angles of $\mathrm{CH}_{3} \mathrm{O}$. Our results are in good agreement with previous DFT results [26]. Second, we examined the structural parameters, upon adsorption. It can be seen from Table 1 that the geometric parameters are independent of number of layers in the slab. Similar structural parameters were calculated for the hollow and bridge- $\mathrm{H}$ hollow sites. The $\mathrm{H}-\mathrm{C}-\mathrm{H}$ angle is increased from $106.4^{\circ}$ (shortest $\mathrm{H}-\mathrm{C}-\mathrm{H}$ angle) in isolated methoxy to $108.5^{\circ}$ (longest $\mathrm{H}-\mathrm{C}-\mathrm{H}$ angle) corresponding to methoxy adsorbed at a bridge- $\mathrm{H}$ hollow site. On the bridge- $\mathrm{H}$ top site the value of this longest $\mathrm{H}-\mathrm{C}-\mathrm{H}$ angle is $108.7^{\circ}$. On the bridge- $\mathrm{H}$ hollow and bridge- $\mathrm{H}$ top sites the longest values of $\mathrm{C}-\mathrm{O}-\mathrm{Au}$ angle are about $120.7^{\circ}$ and $134.3^{\circ}$, respectively. Our values are significantly smaller than that the value $\left(179.2^{\circ}\right)$ obtained par Chen et al. [26] for 
Table 1. Adsorption energies $\left(E_{\text {ads }}\right)$ and geometries for $\mathrm{CH}_{3} \mathrm{O}$ radical at the hollow, bridge-H top and bridge-H hollow, calculated using different numbers of layers in the slab for methoxy coverage of $0.25 \mathrm{ML}$. Numbers in parentheses represent the number of bonds with that length or the number of equal angles.

\begin{tabular}{|c|c|c|c|}
\hline N-layers slabs & & 4-layer $\mathrm{Au}$ & 5-layer Au \\
\hline \multirow{3}{*}{$E_{\text {ads }}(\mathrm{eV})$} & Bridge-H hollow & 1.727 & 2.314 \\
\hline & Bridge-H top & 1.575 & 2.161 \\
\hline & Hollow & 1.697 & 2.283 \\
\hline \multirow{3}{*}{$\mathrm{d}_{\mathrm{C}-\mathrm{H}}(\AA)$} & Bridge-H hollow & $1.103(3)$ & $1.103(3)$ \\
\hline & Bridge-H top & 1.101(1); 1.104(2) & $1.102(1) ; 1.104(2)$ \\
\hline & Hollow & $1.103(3)$ & $1.103(3)$ \\
\hline \multirow{3}{*}{$\mathrm{d}_{\mathrm{C}-\mathrm{O}}(\AA)$} & Bridge-H hollow & 1.422 & 1.424 \\
\hline & Bridge-H top & 1.414 & 1.414 \\
\hline & Hollow & 1.422 & 1.423 \\
\hline \multirow{3}{*}{$\mathrm{d}_{\mathrm{O}-\mathrm{Au}}(\AA)$} & Bridge-H hollow & $2.250(2)$ & $2.250(2)$ \\
\hline & Bridge-H top & $2.195(1) ; 2.197(1)$ & $2.195(1) ; 2.197(1)$ \\
\hline & Hollow & $2.260(2) ; 3.190(2)$ & $2.260(2) ; 3.190(2)$ \\
\hline \multirow{3}{*}{$\mathrm{H}-\mathrm{C}-\mathrm{H}$ angle $\left({ }^{\circ}\right)$} & Bridge-H hollow & $108.3(1) ; 108.5(2)$ & $108.3(1) ; 108.5(2)$ \\
\hline & Bridge-H top & 108.1(2); 108.7(1) & 108.1(2); 108.7(1) \\
\hline & Hollow & $108.2(1) ; 108.5(2)$ & $108.2(1) ; 108.5(2)$ \\
\hline \multirow{3}{*}{$\mathrm{C}-\mathrm{O}-\mathrm{Au}$ angle $\left({ }^{\circ}\right)$} & Bridge-H hollow & $120.6(1) ; 120.7(1)$ & $120.6(2)$ \\
\hline & Bridge-H top & $132.6(1) ; 134.3(1)$ & $132.6(1) ; 134.3(1)$ \\
\hline & Hollow & $122.0(2) ; 134.5(2)$ & $122.0(2) ; 134.6(2)$ \\
\hline \multirow{3}{*}{$\mathrm{H}-\mathrm{C}-\mathrm{O}$ angle $\left(^{\circ}\right)$} & Bridge-H hollow & $109.3(2) ; 112.9(1)$ & $109.3(2) ; 112.9(1)$ \\
\hline & Bridge-H top & $111.0(2) ; 109.9(1)$ & $111.0(2) ; 109.9(1)$ \\
\hline & Hollow & $109.4(2) ; 112.9(1)$ & $109.4(2) ; 112.8(1)$ \\
\hline
\end{tabular}

Table 2. Comparison between our calculations for geometric parameters for free $\mathrm{CH}_{3} \mathrm{O}$ and previous calculated results. Numbers in parentheses represent the number of bonds with that length or the number of equal angles.

\begin{tabular}{ccc}
\hline Geometric parameters & Our work & DFT(GGA $)^{(\mathrm{a})}$ \\
\hline $\mathrm{H}-\mathrm{C}-\mathrm{H}$ angle $\left(^{\circ}\right)$ & $106.6(2) ; 106.4(1)$ & - \\
$\mathrm{H}-\mathrm{C}-\mathrm{O}$ angle $\left(^{\circ}\right)$ & $112.3(2) ; 112.2(1)$ & 1.111 \\
$\mathrm{~d}_{\mathrm{C}-\mathrm{H}}(\AA)$ & $1.119(3)$ & 1.352 \\
$\mathrm{~d}_{\mathrm{C}-\mathrm{O}}(\AA)$ & $1.341(1)$ & \\
\hline
\end{tabular}

${ }^{(a)}$ Reference [26].

$\mathrm{CH}_{3} \mathrm{O} / \mathrm{Cu}(111)$ on the bridge site. For $\mathrm{CH}_{3} \mathrm{O}$ on the bridge $\mathrm{H}$-top site, the $\mathrm{H}-\mathrm{C}-\mathrm{O}$ angle, in the range of $109.9^{\circ}-$ $111.0^{\circ}$, is smaller than that the free methoxy $\left(112.3^{\circ}\right)$, and in good agreement with the theoretical results by Pick $\left(109.9^{\circ}-110.0^{\circ}\right)$ for the adsorbed $\mathrm{CH}_{3} \mathrm{O}$ on $\mathrm{Cu}(100)$ on the bridge site [28].

As Tables 1 and 2 show, the $\mathrm{C}-\mathrm{H}$ bond is reduced from $1.119 \AA$ of the isolated $\mathrm{CH}_{3} \mathrm{O}$ radical to $1.101 \AA$. The optimized $\mathrm{C}-\mathrm{H}$ bond is very similar to the $\mathrm{C}-\mathrm{H}$ bond reported by Pick [28]. The calculated $\mathrm{C}-\mathrm{O}$ bond length for the adsorbed $\mathrm{CH}_{3} \mathrm{O}$, in the range of $1.414-1.424 \AA$, is longer than that of the free species $(1.341 \AA)$, and in excellent agreement with the theoretical results by Pick $(1.420 \AA)[28]$ and Chen et al. (1.408 $\AA)$ [26], and with the experimental results by Hoffmann [7], $1.420(-0.003 /+0.0010) \AA$ and Amemiya et al. [6], $1.460 \pm 0.005 \AA$. Compared with the bridge-H top site, the bridge-H hollow geometry has longer O-Au bonds. In addition, the calculated $\mathrm{d}_{\mathrm{O}-\mathrm{Au}}$ values for the both bridge sites are smaller than the corresponding ones obtained by using DFT/B3LYP for $\mathrm{Au}_{7}$ cluster [23]. Comparing with the ionic radius of $\mathrm{Au}^{+}$and $\mathrm{O}^{2-}$, which are 1.37 and 1.32 $\AA$, respectively, [60]; the values of $\mathrm{d}_{\mathrm{O}-\mathrm{Au}}$ are smaller than the ionic radius sum, indicating the strong interaction between $\mathrm{O}$ of $\mathrm{CH}_{3} \mathrm{O}$ and the surface $\mathrm{Au}$ atom.

\subsubsection{Analysis of Local Density of States (LDOS)}

We now comment on the evolution of the local electronic 
structure of the molecule and the surface upon adsorption for the most stable adsorption site. Figure 2(a) compares the LDOS of $\mathrm{O}$ in $\mathrm{CH}_{3} \mathrm{O}$, adsorbed on a preferred bridge-H hollow site, (continuous curve) to the LDOS of $\mathrm{O}$ in $\mathrm{CH}_{3} \mathrm{O}$, when it is in a gas phase (dashed curve), i.e. in the case of a free $\mathrm{CH}_{3} \mathrm{O}$ radical. The graph obviously falls into two main regions. The first region, from -13 $\mathrm{eV}$ to $-9 \mathrm{eV}$, has essentially a mixed $\left(s+p_{z}\right)$ character for $\mathrm{O}$ atom. Here, the $\mathrm{O}$ density of states can be clearly recognized as they are essentially shifted to lower binding energies by ca. $1.42 \mathrm{eV}$ with respect to the free $\mathrm{CH}_{3} \mathrm{O}$ radical. The second region of the graph is the energy range from $-9 \mathrm{eV}$ to $+2 \mathrm{eV}$. The states represented in this region all contain $\mathrm{O} 2 \mathrm{~s}$ and $\mathrm{O} 2 \mathrm{p}$ characters. One can see from Figure 2(a) that a dramatic change in these orbitals occurs upon adsorption. There is a strong mixing between these orbitals and the $5 \mathrm{~d}$ states of $\mathrm{Au}$, particularly the $d_{x z}$-band of the Au surface.

The $\mathrm{Au}$ surface is affected by the $\mathrm{CH}_{3} \mathrm{O}$ adsorption. By examining the components of the Au-d orbitals, we found that $\mathrm{d} x z$ is the most affected. Figure 2(b) shows the LDOS at a surface gold atom of the bridge-H hollow site (solid line) with the LDOS for a Au atom in the clean surface (dotted line) superimposed. The characters of the two curves are not similar. The LDOS curve for the chemisorption system has a small peak of resonance at $-11.36 \mathrm{eV}$ which is due to density in oxygen $2 \mathrm{~s}$ and $2 p$-derived orbitals lying within the region of the cut. The other notable differences are the presence of two peaks of
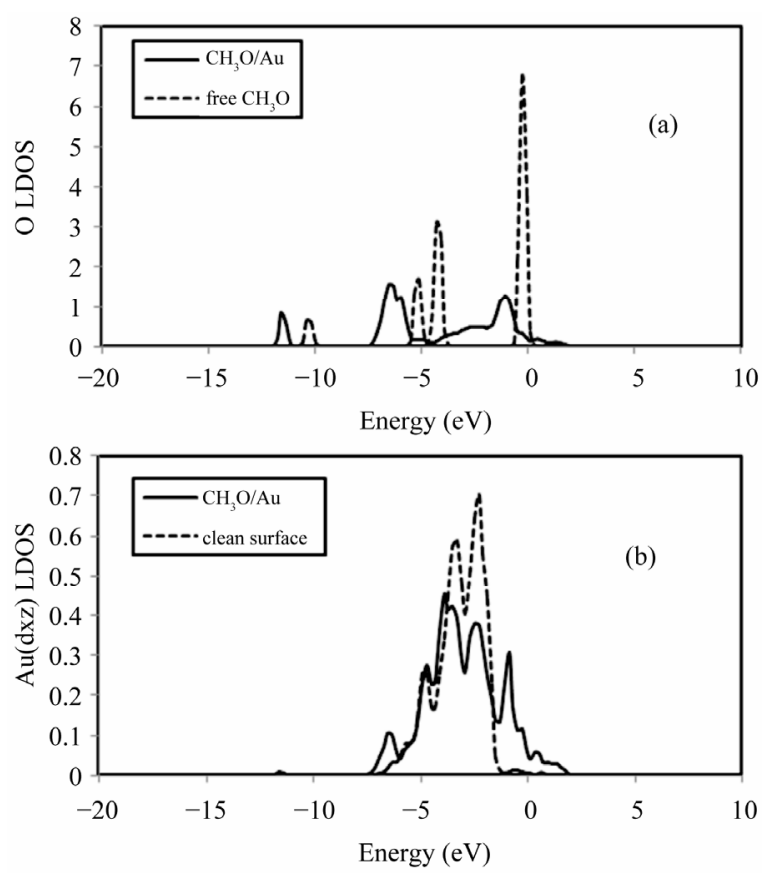

Figure 2. LDOS curves for: (a) $\mathrm{O}$ in the free $\mathrm{CH}_{3} \mathrm{O}$ and $\mathrm{CH}_{3} \mathrm{O} / \mathrm{Au}(100)$; (b) $\mathrm{d}_{x z}$ orbital of Au. The zero energy corresponds to the Fermi level. resonance at about $-6.31 \mathrm{eV}$ and $-0.86 \mathrm{eV}$ in the chemisorption system curve. These peaks of resonance correspond to states with $\mathrm{O} 2 \mathrm{~s}$ and $\mathrm{O} 2 \mathrm{p}$ characters as described previously. In addition, on can notice there is a clear intensity decrease in the $-3.68 \mathrm{eV}$ to $-1.46 \mathrm{eV}$ region, and the appearance of continuously distributed states from $-0.25 \mathrm{eV}$ up to the Fermi level.

\subsection{H Adsorption on Au(100) Surface}

\subsubsection{Chemisorption Energies and Geometrical Parameters}

In this subsection, we investigate the adsorption of $\mathrm{H}$ on $\mathrm{Au}(100)$ surface. The adsorption energy for atomic hydrogen is calculated by the equation:

$$
E_{\mathrm{ads}}=\left[E_{\mathrm{Au}(100)}+n E_{\mathrm{H} 2} / 2-E_{n \mathrm{H} / \mathrm{Au}(100)}\right] / n
$$

where $n$ is the number of $\mathrm{H}$ atoms in the surface unit, $E_{n \mathrm{H} / \mathrm{Au}(100)}$ and $E_{\mathrm{Au}(100)}$ are the energies of the $\mathrm{Au}(100)$ system with and without $n \mathrm{H}$ absorbates, while $E_{\mathrm{H} 2}$ is the ground state energy of a free $\mathrm{H}_{2}$ molecule. The first and last terms are calculated with the same parameters $(\mathrm{k}$ sampling, energy cutoff, etc.). The second term is calculated with only the $\Gamma$-point for the Brillouin zone sampling. With this definition, a positive $E_{\text {ads }}$ corresponds to a stable adsorption on the slab.

The energy of the free hydrogen molecule was determined from calculations performed on a single hydrogen molecule in a cubic cell with an edge of $15 \AA$. We made sure that the properties of the free $\mathrm{H}_{2}$ molecule were accurately reproduced. Table $\mathbf{3}$ compares the calculated and experimental bond lengths $\mathrm{d}_{\mathrm{H}-\mathrm{H}}$ for gas-phase hydrogen. Our calculated result $(0.7600 \AA)$ can be compared with the experimental value of $0.7414 \AA$ [57]. Our bigger result is however in excellent agreement with other theoretical evaluation using similar methods $[43,61,62]$.

We start by considering the on-top and bridge adsorption of $\mathrm{H}$ on $\mathrm{Au}(100)$ for coverages of $0.25 \mathrm{ML}$ and 0.5 ML. The hollow site was found to be unstable, the atom moving to the bridge site during geometry optimization. This phenomenon was also observed by Moussounda et al. [49] and Saad et al. [47] on the adsorption of $\mathrm{H}$ on $\mathrm{Pt}(100)$. The adsorption energies for different number of layers in the slab and different coverages are reported in Table 4. It might be surprising to find a desorption energy for $\mathrm{H}$ in the case of the 4-layer slab for the two coverages, in other terms, the 4-layer slab is predicted to be endothermic with respect to gaseous $\mathrm{H}_{2}$ and a clean $\mathrm{Au}$ surface. These observations are consistent with the theoretical results reported by Sundell et al. [53], and Jiang et al. [63] and Fabiani et al. [64] for $\mathrm{H} / \mathrm{Cu}(001)$ and $\mathrm{H} / \mathrm{Fe}(100)$, respectively. Our results reveal that hydrogen preferred adsorbs at the bridge site on $\mathrm{Au}(100)$ for the 5-layer slab. The adsorption energy of bridged bonded 
Table 3. Comparison between the calculated and experimental bond lengths $\mathrm{d}_{\mathrm{H}-\mathrm{H}}$ of free hydrogen molecule.

\begin{tabular}{|c|c|c|c|c|c|c|}
\hline \multirow[b]{2}{*}{$\mathrm{d}_{\mathrm{H}-\mathrm{H}}$} & \multirow{2}{*}{$\begin{array}{c}\text { Our work } \\
0.7600\end{array}$} & \multicolumn{4}{|c|}{ DFT(GGA) } & xperimental value \\
\hline & & $0.7557^{(a)}$ & $0.7488^{(\mathrm{b})}$ & $0.7520^{(\mathrm{c})}$ & $0.7500^{(\mathrm{d})}$ & $0.7414^{(\mathrm{e})}$ \\
\hline
\end{tabular}

(a) Reference [61], ${ }^{(\mathrm{b})}$ Reference [50], ${ }^{(\mathrm{c})}$ Reference [43], ${ }^{(\mathrm{d})}$ Reference [62], ${ }^{(\mathrm{e})}$ Reference [57].

Table 4. Adsorption energies $\left(E_{\text {ads }}\right)$ and bond lengths $\left(d_{H-A u}\right)$ obtained for hydrogen adsorbed at the top and bridge sites of Au(100).

\begin{tabular}{lcccccc}
\hline \multirow{2}{*}{ H coverage } & & \multicolumn{3}{c}{$0.25 \mathrm{ML}$} & \multicolumn{2}{c}{$0.50 \mathrm{ML}$} \\
\cline { 3 - 6 } & & 4-layer Au & 5-layer Au & 4-layer Au & 5-layer Au \\
\hline \multirow{2}{*}{$E_{\text {ads }}(\mathrm{eV})$} & Top & -0.337 & 0.234 & -0.344 & -0.072 \\
& Bridge & -0.030 & 0.568 & -0.030 & 0.241 \\
\multirow{2}{*}{$\mathrm{d}_{\mathrm{H}-\mathrm{Au}}(\AA)$} & Top & 1.609 & 1.610 & 1.608 & 1.610 \\
& Bridge & 1.790 & 1.780 & 1.790 & 1.790 \\
\hline
\end{tabular}

$\mathrm{H}$ decreases significantly with the increasing $\mathrm{H}$ coverage. At the coverage of $0.25 \mathrm{ML}$, we found an adsorption energy of $0.568 \mathrm{eV}$. No calculations of hydrogen adsorption on $\mathrm{Au}(100)$ have been published. However, comparative values calculated at the same $\mathrm{H}$ coverage of 0.25 ML for adsorption in bridge site on $\operatorname{Pt}(100)$ and $\operatorname{Pt}(110)$ are $0.610 \mathrm{eV}$ [49] and $0.640 \mathrm{eV}$ [64], respectively. Lai et al. [50] obtained an adsorption energy of $0.542 \mathrm{eV}$ for $\mathrm{H} / \mathrm{Ni}(100)$. Kresse et al. [62] reported an adsorption energy of $0.567 \mathrm{eV}$ for $\mathrm{H} / \mathrm{Ni}(100)$, which is in good agreement with our value.

From Table 4, we note the $\mathrm{d}_{\mathrm{H}-\mathrm{Au}}$ bond lengths for both sites. The $\mathrm{H}-\mathrm{Au}$ distance does not depend on the coverage and increases as usual with the adsorption surface coordination of the adsorbate (1.610 $\AA$ and $1.790 \AA$ for top and bridge sites, respectively). Theoretical calculations using similar method for $\mathrm{H} / \mathrm{Pt}(100)$ [49] found the same result for top and bridge sites (1.572 $\AA$ and $1.763 \AA$, respectively). DFT calculations, using DACAPO package [46], obtained a similar H-Pt bond length for adsorption of $\mathrm{H}$ on-top of $\mathrm{Pt}(111)$ (1.570 $\AA$ ). With hydrogen in the unstable top site, our $\mathrm{H}-\mathrm{Au}$ bond length $(1.61 \AA)$ is somewhat higher than the theoretical result published by Haroun et al. [52] who have reported $1.46 \AA$ for $\mathrm{H} / \mathrm{Ni}(111)$.

\subsubsection{LDOS Calculations}

In order to obtain a deeper understanding of the properties of $\mathrm{H} / \mathrm{Au}(100)$, we have also analyzed their local density of states (LDOS), in the most stable energetically site for $0.25 \mathrm{ML}$. The $\mathrm{H}$ LDOS for an adsorbed $\mathrm{H}$ on $\mathrm{Au}(100)$ for the bridge site is shown in Figure 3 as well as the corresponding LDOS of a free $\mathrm{H}$ atom. We can see that the state situated at $\sim-5.30 \mathrm{eV}$ initially is found dispersed on a largest domain of energy $(\sim 10 \mathrm{eV})$. The $\mathrm{H} 1 \mathrm{~s}$ band has a strong interaction with Au bands, as seen by



Figure 3. LDOS of H-1s orbital. The zero energy corresponds to the Fermi level.

the significant change of the Au s, $\mathrm{p}_{y}, \mathrm{~d}_{x x-y y}$ and $\mathrm{d}_{y z}$ LDOS for the bridge site (Figures 4 and 5). Several peaks of resonance appear on the $\mathrm{Au} \mathrm{p}_{y} \operatorname{LDOS}$ (Figure 4(b)), the peaks increase in intensity and we can see in Figures 4(a) and 5 (b) the strong shift of $\mathrm{s}$ and $\mathrm{d}_{y z}$ centre of gravity, respectively. This is clearly due to the hybridization between 1s state of $\mathrm{H}$ and s-p-d Au states after H adsorption.

\section{Conclusion}

We performed all-electron periodic DFT-GGA calculations of the adsorption of $\mathrm{CH}_{3} \mathrm{O}$ and $\mathrm{H}$ on $\mathrm{Au}(100)$. For methoxy radical, we found that the $\mathrm{CH}_{3} \mathrm{O}$ adsorption energy depends strongly on number of layers in the slab and increases with increases in number of layers in the slab. The electronic structure analysis of the adsorbed $\mathrm{CH}_{3} \mathrm{O}$ shows that there is a pronounced hybridization between the $\mathrm{O} 2 \mathrm{~s}, 2 \mathrm{p}$ orbitals and $\mathrm{d}_{x z}$-band of the Au surface. For atomic hydrogen, the desorption is found to be favorable for the 4-layer slab. The local density of states curves around $\mathrm{H}$ of the adsorbed hydrogen show dispersed states below the metal Fermi level indicating an 


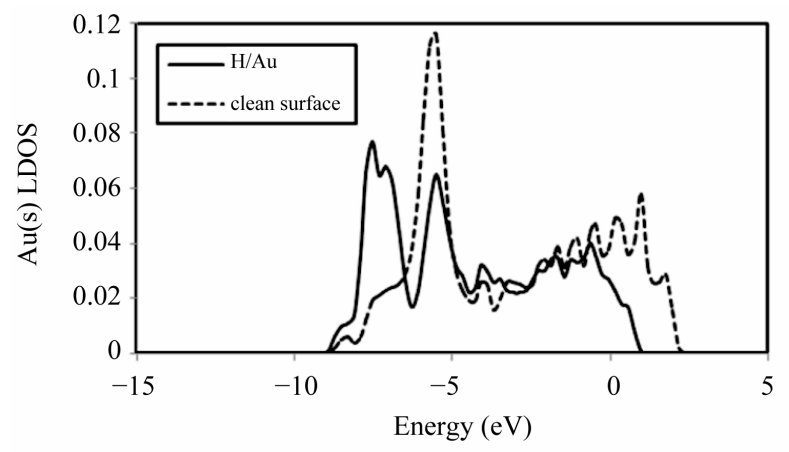

(a)

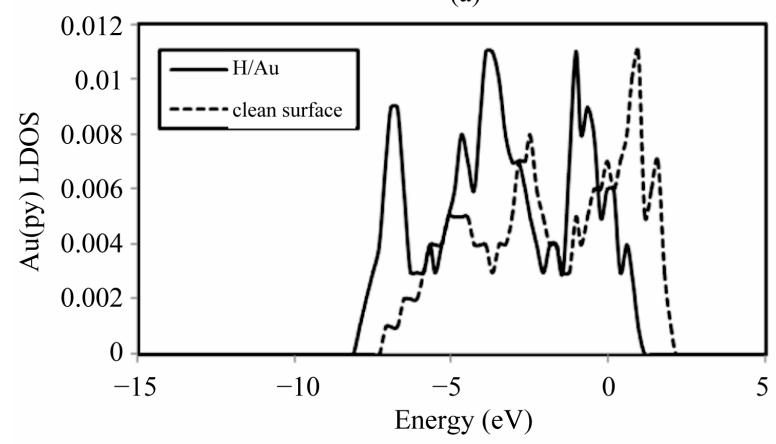

(b)

Figure 4. LDOS of Au band after $\mathrm{H}$ adsorption on $\mathrm{Au}(100)$ : (a) s; (b) $p_{y}$ [solid curves]. The dashed curves indicate the Au orbitals before adsorption of $\mathbf{H}$. The Fermi level lies at 0 eV.

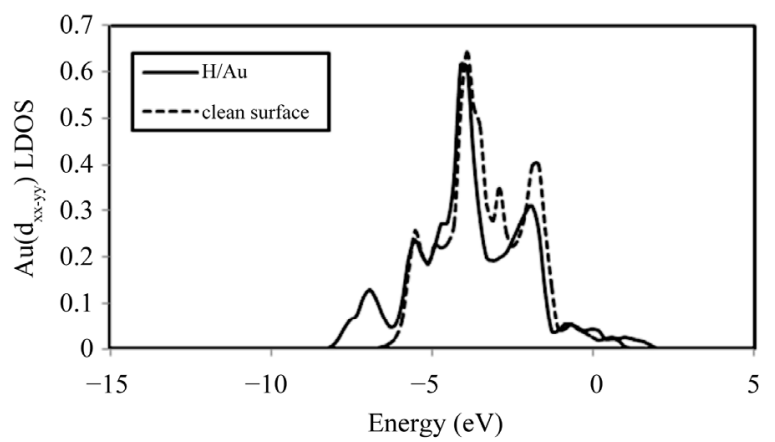

(a)

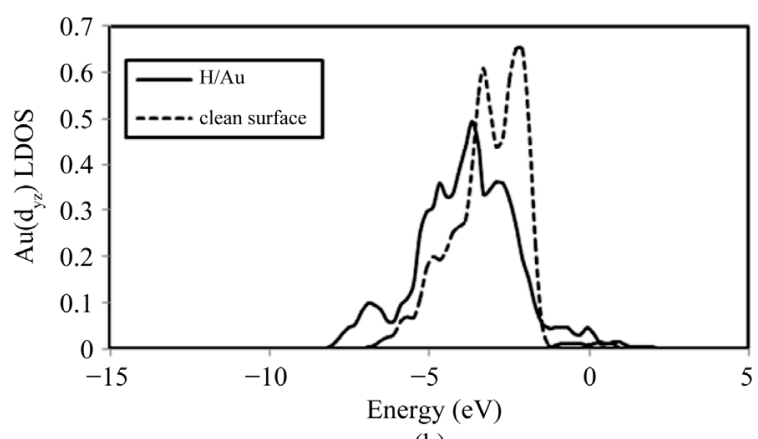

(b)

Figure 5. LDOS of Au band after $\mathrm{H}$ adsorption on $\mathrm{Au}(100)$ : (a) $d_{x x-y y}$, (b) $d_{y z}$ [solid curves]. The dashed curves indicate the Au orbitals before adsorption of $\mathrm{H}$. The Fermi level lies at $0 \mathrm{eV}$.
$\mathrm{H}-\mathrm{Au}$ mixing demonstrating a chemical interaction.

\section{Acknowledgements}

PS Moussounda acknowledge the "Ecole de Chimie, Polymères et Matériaux de Strasbourg (ECPM) and the "Université de Strasbourg (UDS)" for their financial support and the "Laboratoire des Matériaux, Surfaces et Procédés pour la Catalyse" of the "Université de Strasbourg (UDS)" for access to computational resources.

\section{REFERENCES}

[1] C. Barnes, P. Pudney, Q. Guo and M. Bowker, "Molecular-Beam Studies of Methanol Partial Oxidation on $\mathrm{Cu}(110)$," Journal of the Chemical Society, Faraday Transactions, Vol. 86, No. 15, 1990, pp. 2693-2699. doi: $10.1039 / \mathrm{ft} 9908602693$

[2] S. M. Francis, F. M. Leibsle, S. Haq, N. Xiang and M. Bowker, "Methanol Oxidation on Cu(110)," Surface Science, Vol. 315, No. 3, 1994, pp. 284-292. doi:10.1016/0039-6028(94)90132-5

[3] M. Bader, A. Puschmann and J. Haase, "Orientation of $\mathrm{CH}_{3} \mathrm{O}$ on $\mathrm{Cu}(110)$ as Examined by Near-Edge X-Ray Absorption Fine Structure Spectroscopy," Physical Review B, Vol. 33, No. 10, 1986, pp. 7336-7338. doi:10.1103/PhysRevB.33.7336

[4] E. Holub-Krappe, K. C. Prince, K. Horn and D. P. Woodruff, "X-Ray Photoelectron Diffraction Determination of the Molecular Orientation of CO and Methoxy Adsorbed on $\mathrm{Cu}(110)$," Surface Science, Vol. 173, No. 1, 1986, pp. 176-193. doi:10.1016/0039-6028(86)90115-9

[5] A. V. de Carvalho, M. C. Asensio and D. P. Woodruff, "Determination of the Orientation of Methoxy on $\mathrm{Cu}(111)$ Using X-Ray Photoelectron Diffraction," Surface Science, Vol. 273, No. 3, 1992, pp. 381-384. doi:10.1016/0039-6028(92)90075-H

[6] K. Amemiya, Y. Kitajima, Y. Yonamoto, S. Terada, H. Tsukabayashi, T. Yokoyama and T. Ohta, "Oxygen K-Edge X-Ray-Absorption Fine-Structure Study of Surface Methoxy Species on $\mathrm{Cu}(111)$ and $\mathrm{Ni}(111)$," Physical Review B, Vol. 59, No. 3, 1999, pp. 2307-2312. doi:10.1103/PhysRevB.59.2307

[7] P. Hofmann, K. M. Schindler, S. Bao, V. Fritzsche, D. E. Ricken, A. M. Bradshaw and D. P. Woodruff, "The Geometric Structure of the Surface Methoxy Species on Cu(111)," Surface Science, Vol. 304, No. 1-2, 1994, pp. 74-84. doi:10.1016/0039-6028(94)90754-4

[8] R. Ryberg, "The Oxidation of Methanol on $\mathrm{Cu}(100)$," Journal of Chemical Physics, Vol. 82, No. 1, 1985, pp. 567573. doi:10.1063/1.448729

[9] D. A. Outka, R. J. Madix and J. Stoehr, "Structural Studies of Formate and Methoxy Groups on the $\mathrm{Cu}(100)$ Surface NEXAFS and SEXAFS," Surface Science, Vol. 164, No. 1, 1985, pp. 235-259. doi:10.1016/0039-6028(85)90710-1

[10] R. Ryberg, "Symetry and Orientation of $\mathrm{CH}_{3} \mathrm{O}$ on $\mathrm{Cu}(100)$," Physical Review B, Vol. 31, No. 4, 1985, pp. 2545-2547. 


\section{doi:10.1103/PhysRevB.31.2545}

[11] R. Ryberg, "CH Stretch Vibrations of Adsorbed Molecules Studied by Infrared Spectroscopy: $\mathrm{CH}_{3} \mathrm{O}$ on $\mathrm{Cu}(100)$," Chemical and Physics Letters, Vol. 83, No. 3, 1981, pp. 423-426. doi:10.1016/0009-2614(81)85493-0

[12] J. P. Camplin and E. M. McCash, "ARAIRS Study of Methoxy and Ethoxy on Oxidized $\mathrm{Cu}(100)$," Surface Science, Vol. 360, No. 1-3, 1996, pp. 229-241. doi:10.1016/0039-6028(96)00641-3

[13] T. Lindner, J. Somers, A. M. Bradshaw, A. L. D. Kilcoyne and D. P. Woodruff, "A Photoelectron Diffraction and NEXAFS Study of the Structure of the Methoxy Species (CH3O-) on $\mathrm{Cu}(100)$," Surface Science, Vol. 203, No. 3, 1988, pp. 333-352. doi:10.1016/0039-6028(88)90087-8

[14] W. S. Sim, P. Gardner and D. A. King, "Structure and Reactivity of the Surface Methoxy Species on $\operatorname{Ag}(111)$," Journal of Physical Chemistry, Vol. 99, No. 43, 1995, pp. 16002-16010. doi:10.1021/j100043a046

[15] L. J. Richer and W. Ho, "Reactive Adsorption of $\mathrm{H}_{2} \mathrm{CO}$ on $\mathrm{Ni}(110)$ at 95K," Journal of Chemical Physics, Vol. 83, No. 5, 1985, pp. 2165-2169. doi:10.1063/1.449308

[16] H. E. Dastoor, P. Gardner and D. A. King, "Identification of Two Telted Adsorbed $\mu 2-$ Methoxy Species on Ni(110 Using RAIRS," Chemical Physics Letters, Vol. 209, No. 5-6, 1993, pp. 493-498.

[17] A. Emundts, G. Pirug, J. Werner and H. P. Bonzel, "Large Solid Angle X-Ray Photoelectron Intensity Distributions from CO, Methoxy and Formate Adsorbed on Ni(110)," Surface Science, Vol. 410, No. 2-3, 1998, pp. L727-L735. doi:10.1016/S0039-6028(98)00233-7

[18] B. Sexton, "Methanol Decomposition on Platinum(111)," Surface Science, Vol. 102, No. 1, 1981, pp. 271-281. doi:10.1016/0039-6028(81)90321-6

[19] M. Witko, K. Hermann, D. Ricken, W. Stenzel, H. Con$\mathrm{rad}$ and A. M. Bradshaw, "The Electron Structure of the Surface Methoxy Species on $\mathrm{Cu}(111)$," Chemical Physics, Vol. 177, No. 2, 1993, pp. 363-371. doi:10.1016/0301-0104(93)80018-5

[20] H. Yang, J. L. Whitten and C. M. Friend, "Adsorption of $\mathrm{CH}_{3} \mathrm{O}$ on $\mathrm{Ni}(111)$," Surface Science, Vol. 313, No. 3, 1994, pp. 295-307. doi:10.1016/0039-6028(94)90050-7

[21] M. Witko and K. Hermann, "Site-Dependent Binding of Methoxy on $\mathrm{Cu}(111)$ : Cluster Model Studies," Journal of Chemical Physics, Vol. 101, No. 11, 1994, pp. 1017310180. doi:10.1063/1.468006

[22] G. C. Wang, Y. H. Zhoua, Y. Morikawa, J. Nakamura, Z. S. Cai and X. Z. Zhao, "Kinetic Mechanism oh Methanol Decomposition on Ni(111) Surface: A Theoretical Study," Journal of Physical Chemistry B, Vol. 109, No. 25, 2005, pp. 12431-12442. doi:10.1021/jp0463969

[23] J. R. B. Gomes and J. A. N. F. Gomes, "Comparative Study of Geometry and Bonding Character for Methoxy Radical Adsorption on Noble Metals," Journal of Molecular Structure (Theochem), Vol. 503, No. 3, 2000, pp. 189-200. doi:10.1016/S0166-1280(99)00286-9

[24] J. Greeley and M. Mavrikakis, "Competitive Paths for Methanol Decomposition on Pt(111)," Journal of American Chemical Society, Vol. 126, No. 10, 2004, pp. 3910-

\section{9. doi:10.1021/ja037700z}

[25] X. Y. Pang, C. Wang, Y. H. Zhou, J. M. Zhao and G. C. Wang, "DFT Study of the Structure Sensitivity for the Adsorption of Methyl, Methoxy, and Formate on Ni(111), $\mathrm{Ni}(100)$, and Ni(110) Surfaces," Journal of Molecular Structure (Theochem), Vol. 948, No. 1-3, 2010, pp. 1-10. doi:10.1016/j.theochem.2010.01.034

[26] W. K. Chen, S. H. Liu, M. J. Cao, Q. G. Yan and C. H. $\mathrm{Lu}$, "Adsorption and Dissociation of Methanol on $\mathrm{Au}(111)$ Surface: A First-Principles Periodic Density Functional Study," Journal of Molecular Structure (Theochem), Vol 770, No. 1-3, 2006, pp. 87-91. doi:10.1016/j.theochem.2006.05.040

[27] W. K. Chen, S. H. Liu, M. J. Cao, C. H. Lu, Y. Xu and J. Q. Li, "Adsorption of Methanol and Methoxy on $\mathrm{Cu}(111)$ Surface: A First-Principles Periodic Density Functional Theory Study," Chinical Journal of Chemistry, Vol. 24, No. 7, 2006, pp. 872-876. doi:10.1002/cjoc.200690166

[28] S. Pick, "Density-Functional Study of the Methoxy Intermediates at $\mathrm{Cu}(111), \mathrm{Cu}(110)$ and $\mathrm{Cu}(001)$ Surfaces," Journal of Physics: Condensed Matterials, Vol. 22, No. 39, 2010, Article ID: 395002.

[29] K. Christmann, "Interaction of Hydrogen with Solid Surfaces," Surface Science, Vol. 9, No. 1-3, 1988, pp. 1-163. doi:10.1016/0167-5729(88)90009-X

[30] G. A. Somorjai, "Introduction to Surface Chemistry and Catalysis," Wiley-Interscience, New York, 1994.

[31] M. Schick, J. Lauterbach and W. Weinberg, "The CO Adsorption of Hydrogen and Potassium on $\operatorname{Ir}(111)$," Surface Science, Vol. 360, No. 1-3, 1996, pp 255-260. doi:10.1016/0039-6028(96)00666-8

[32] H. Okuyama, T. Ueda, T. Aruga and M. Nishijima, "Overtones of $\mathrm{H}$ Vibrations at $\mathrm{Ni}(111)$ : Formation of Delocalized States," Physical Review B, Vol. 63, No. 23, 2001, pp. 233403-233406. doi:10.1103/PhysRevB.63.233403

[33] G. X. Cao, E. Nabighian and X. D. Zhu, "Diffusion of Hydrogen on Ni(111) over Wide Range of Temperature: Exploring Quantum Diffusion on Metals," Physial Review Letters, Vol. 79, No. 19, 1997, pp. 3696-3699. doi:10.1103/PhysRevLett.79.3696

[34] A. E. Morgan and G. A. Somorjai, "LEED Studies of Gas Adsorption on the Platinum (100) Single Crystal Surface," Surface Science, Vol. 12, No. 3, 1968, pp. 405-425. doi:10.1016/0039-6028(68)90089-7

[35] R. W. McCabe and L. D. Schmidt, "Adsorption on $\mathrm{H}_{2}$ and $\mathrm{CO}$ on Clean and Oxidized (110) Pt," Surface Science, Vol. 60, No. 1, 1976, pp. 85-98 doi:10.1016/0039-6028(76)90008-X

[36] K. Christmann, G. Ertl and T. Pignet, "Adsorption of Hydrogen on a Pt(111) Surface," Surface Science, Vol. 54, No. 2, 1976, pp. 365-392. doi:10.1016/0039-6028(76)90232-6

[37] J. R. Engstrom, W. Tsai and W. H. Weinberg, "The Chemisorption of Hydrogen on the $\operatorname{Pt}(111)$ and (110)-(1x2) Surfaces of Iridium and Platinum," Journal of Chemical Physics, Vol. 87, No. 5, 1987, pp. 3104-3119. doi:10.1063/1.453048

[38] L. J. Richter, "Vibrational Spectroscopy of H on Pt(111): Evidence for Universally Soft Parallel Modes," Physical 
Review B, Vol. 36, No. 18, 1987, pp. 9797-9800. doi:10.1103/PhysRevB.36.9797

[39] B. J. J. Koelman, S. T. de Zwart, A. L. Boers, B. Poelsema and L. K. Verheij, "Information on Adsorbate Positions from Low-Energy Recoil Scattering: Adsorption of Hydrogen on Pt," Physical Review Letters, Vol. 56, No. 11, 1986, pp. 1152-1155. doi:10.1103/PhysRevLett.56.1152

[40] W. Di, K. E. Smith and S. D. Kevan, "Angle-Resolved Photoemission Study of the Clean and Hydrogen-Covered Pt(111) Surface," Physical Review B, Vol. 45, No. 7, 1992, pp. 3652-3658. doi:10.1103/PhysRevB.45.3652

[41] B. E. Spiewak, R. D. Cotright and J. A. Dumesic, "Microcalorimetric Studies of $\mathrm{H}_{2}, \mathrm{C}_{2} \mathrm{H}_{4}$ and $\mathrm{C}_{2} \mathrm{H}_{2}$ Adsorption on Pt Powder," Journal of Catalysis, Vol. 176, No. 2, 1998, pp. 405-414. doi:10.1006/jcat.1998.2047

[42] P. Nordlander, S. Holloway and J. K. Nørskov, "Hydrogen Adsorption on Metal Surfaces," Surface Science, Vol. 136, No. 1, 1984, pp. 59-81. doi:10.1016/0039-6028(84)90655-1

[43] D. E. Jiang and E. A. Carter, "Adsorption and Diffusion Energetics of Hydrogen Atoms on $\mathrm{Fe}(110)$ from First Principles," Surface Science, Vol. 547, No. 1-2, 2003, pp. 85-98. doi:10.1016/j.susc.2003.10.007

[44] P. Légaré, "A Theoretical Study of H Surface and Subsurface Species on Pt(111)," Surface Science, Vol. 559, No. 2-3, 2004, pp. 169-178. doi:10.1016/j.susc.2004.04.013

[45] F. Faglioni and W. A. Goddard III, "Energetics of Hydrogen Coverage on Group VIII Transition Metal Surfaces and Kinetic Model for Adsorption/Desorption," Journal of Chemical Physics, Vol. 122, No. 1, 2005, Article ID: 014704. doi:10.1063/1.1814938.

[46] D. C. Ford, Y. Xu and M. Mavrikakis, "Atomic and Molecular Adsorption on Pt(111)," Surface Science, Vol. 587, No. 3, 2005, pp. 159-174. doi:10.1016/j.susc.2005.04.028

[47] F. Saad, M. Zemerli, M. Bennaki and S. Bouarab, "AbInitio Study of Coadsorption of $\mathrm{Li}$ and $\mathrm{H}$ on $\mathrm{Pt}(001)$, Pt(110) and Pt(111) Surfaces," Physica B, Vol. 407, No. 4, 2012, pp. 698-704. doi:10.1016/j.physb.2011.12.005

[48] M. A. Petersen, S. J. Jenkins and D. A. King, "Theory of Methane Dehydrogenation on Pt $\{110\}$ (1x2). Part I: Chemisorption of CHx (x = $0-3)$," Journal of Physical Chemistry B, Vol. 108, No. 19, 2004, pp. 5909-5919. doi:10.1021/jp037880z

[49] P. S. Moussounda, M. F. Haroun, G. Rakotovelo and P. Légaré, "A Theoretical Study of $\mathrm{CH}_{4}$ Dissociation on Pt(100)," Surface Science, Vol. 601, No. 18, 2007, pp. 3697-3701. doi:10.1016/j.susc.2007.04.014

[50] W. Lai, D. Xie and D. H. Zhang, "First-Principles Study of Adsorption of Methyl, Coadsorption of Methyl and Hydrogen, and Methane Dissociation on Ni(100)," Surface Science, Vol. 594, No. 1-3, 2005, pp. 83-92. doi:10.1016/j.susc.2005.07.012

[51] J. Greeley and M. Mavrikakis, "A First-Principles Study of Surface and Subsurface H on and in Ni(111): Diffusional Properties and Coverage-Dependent Behavior," Surface Science, Vol. 540, No. 2-3, 2003, pp. 215-229.

\section{doi:10.1016/S0039-6028(03)00790-8}

[52] M. F. Haroun, P. S. Moussounda, P. Légaré and J. C. Parlebas, "Adsorption and Co-Adsorption of $\mathrm{CH}_{3}$ and $\mathrm{H}$ on Flat and Defective Nickel (111) Surfaces," European Physical Journal B, Vol. 7, No. 3, 2010, pp. 353-358. doi:10.1140/epjb/e2010-10680-0

[53] P. G. Sundell and G. Wahnström, "Hydrogen Tunneling on a Metal Surface: A Density-Functional Study of $\mathrm{H}$ and D Atoms on $\mathrm{Cu}(001)$," Surface Science, Vol. 593, No. 1-3, 2005, pp. 102-109. doi:10.1016/j.susc.2005.06.051

[54] B. Hammer, L. B. Hansen and J. K. Nørkov, "Improved Adsorption Energetics within Density-Functional Theory Using Revised Perdew-Burke-Ernzerhof Functionals," Physical Review B, Vol. 59, No. 11, 1999, pp. 7413-7421. doi:10.1103/PhysRevB.59.7413

[55] D. Vanderbilt, "Soft Self-Consistent Pseudopotentials in a Generalized Eigenvalue Formalism," Physical Review B, Vol. 41, No. 11, 1990, pp. 7892-7895. doi:10.1103/PhysRevB.41.7892

[56] J. P. Perdew, J. A. Chevary, S. H. Vosko, K. A. Jackson, M. R. Pederson, D. J. Singh and C. Fiolhais, "PW91: Atoms, Molecules, Solids, and Surfaces: Applications of the Generalized Gradient Approximation for Exchange and Correlation," Physical Review B, Vol. 46, No. 11, 1992, pp. 6671-6687. doi:10.1103/PhysRevB.46.6671

[57] D. R. Lide, "CRC Handbook of Chemistry and Physics," CRC Press, Boca Raton, 1996.

[58] B. Xu, J. Haubrich, T. A. Baker, E. Kaxiras and C. M. Friend, "Theoretical Study of O-Assisted Selective Coupling of Methanol on Au(111)," Journal of Physical Chemistry, Vol. 115, No. 5, 2011, pp. 3703-3708. doi:10.1021/jp110835w

[59] F. Mehmood, A. Kara, T. S. Rahman and C. R. Henry, "Comparative Study of CO Adsorption on Flat, Stepped and Kinked Au Surfaces Using Density Functional Theory," Physical Review B, Vol. 79, No. 7, 2009, Article ID: 075422.

[60] F. Herzberg, "Molecular Spectra and Molecular Structure. II. Infrared and Raman Spectra of Polyatomic Molecules,” D. Van Nostrand Company, New York, 1945.

[61] P. S. Moussounda, "Adsorption et Activation du Méthane et du Méthanol sur la Surface (100) du Platine: Une Etude par la Fonctionnelle de la Densité," Ph.D. Thesis, University of Louis Pasteur Strasbourg 1, Strasbourg, 2006.

[62] G. Kresse and J. Hafner, "First Principles Study of the Adsorption of Atomic H on the Ni(111), (100), (110) Surfaces," Surface Science, Vol. 459, No. 3, 2000, pp. 287302. doi:10.1016/S0039-6028(00)00457-X

[63] D. E. Jiang and E. A. Carter, "Diffusion of Interstitial Hydrogen into and through bcc Fe from First Principles," Physical Review B, Vol. 70, No. 6, 2004, Article ID: 064102.

[64] F. C. Fabiani, G. Fratesi and G. P. Brivio, "Adsorption of $\mathrm{H}_{2} \mathrm{~S}, \mathrm{HS}, \mathrm{S}$ and $\mathrm{H}$ on a Stepped $\mathrm{Fe}(310)$ Surface," European Physical Journal B, Vol. 78, No. 4, 2010, pp. 455460. 